\title{
Pragmatics and the Challenge of 'Non-Propositional' Effects
}

\section{Deirdre Wilson and Robyn Carston}

[Forthcoming in Journal of Pragmatics 2019]

\begin{abstract}
Although some utterances communicate a determinate speaker's meaning which can be duplicated in the minds of speaker and hearer, others communicate - either alongside or instead of a speaker's meaning - something much less determinate, often described as a 'non-propositional effect'. Creative metaphors, for instance, are seen as conveying loose impressions, perhaps interspersed with images, which vary from one addressee to another, and typically activate perceptual, emotional or sensorimotor mechanisms. After illustrating the notion of a non-propositional effect and outlining some of the challenges these interpretive effects present for current linguistic approaches to pragmatics, we consider how they might be dealt with in more cognitively oriented approaches such as relevance theory, and what role mental imagery might play in metaphor interpretation in particular.
\end{abstract}

Keywords: speaker's meaning, indeterminacy, weak implicature, metaphor, mental imagery

\section{Introduction}

Among those who see pragmatics as primarily concerned with providing a theory of communication rather than an investigation of language use, the scope of pragmatics is generally thought of as delimited by Grice's notion of non-natural meaning (meaning ${ }_{N N}$ ), or speaker's meaning. ${ }^{1}$ As Stephen Levinson (2000: 12-13) puts it,

\footnotetext{
1 Grice's term was 'utterer's meaning', where an 'utterance' is an overtly intentional attempt - whether verbal or non-verbal - to produce a certain cognitive or behavioural response in an addressee. We will use 'speaker's meaning' in the same broad sense.
} 
A theory of communication has as its target the full scope of Grice's (1957) non-natural meaning ... [M]eaning $\mathrm{N}_{\mathrm{NN}}$ (or something of the sort) draws an outer boundary on the communicational effects that a theory of communication is responsible for.

Grice's definition of speaker's meaning was designed to pick out a certain subtype of overt intentional communication involving a series of nested intentions. In order to mean $\mathrm{N}_{\mathrm{N}}$ something by a declarative utterance, a speaker must intend the addressee (a) to form a certain belief, (b) to recognise that she intends him to form that belief, and (c) to form that belief at least partly on the basis of recognising that she intends him to form it. What is communicated in (1b), for instance, where Sue asserts that she enjoyed some of the meal and implicates that she didn't enjoy all of it, can be straightforwardly described as a speaker's meaning:
a. Jack: Did you enjoy the meal?
b. Sue: I enjoyed some of it

Grice's definition was designed to cover certain cases of non-verbal communication but exclude others: for instance, showing someone a photograph which proves conclusively (quite independently of the communicator's intentions) that he was present on a certain occasion would not satisfy clause (c) (Grice, 1957/1989: 218). Levinson's proposal would exclude this further range of overtly intentional communicative acts from the scope of pragmatics.

As standardly conceived in linguistic pragmatics and philosophy of language, a speaker's meaning has several distinctive properties. It can be

- rendered without loss as a single proposition, or a small set of propositions;

- duplicated in the minds of speaker and hearer; and therefore 
- added to the common ground and taken for granted in the rest of the conversation.

However, most uses of language also communicate (in an overtly intentional way), something less determinate and more nuanced than a speaker's meaning. What is communicated by use of the creative metaphor in (2) might be best described as a loose impression, perhaps interspersed with images, that lacks the distinctive properties listed above:

(2) ... a heron launched itself from low ground to our south, a foldaway construction of struts and canvas, snapping and locking itself into shape just in time to keep airborne, ... (Macfarlane, 2013: 298-299)

The resulting interpretation cannot be rendered without loss as a single proposition (or a small set of propositions) that can be duplicated in the minds of communicator and addressee(s). ${ }^{2}$ Parallel points apply to the lexical adjustments in (3) (where kill is traditionally analysed as a hyperbole, glass as a loose use and water as a case of lexical narrowing), and to expressions of affective attitude, as in the ironical (4) and the parodic (5):

(3) I could kill for a glass of water. (Sperber and Wilson, 2015: 121)

(4) A: What if the USSR blockades the Gulf and all the oil?

B: Oh come now, Britain rules the seas! (Levinson, 1983: 109)

(5) A: I don't like this awful weather

B (in exaggeratedly feeble and whining tones): I don't like this awful weather

\footnotetext{
2 In comparing our own interpretations of (2), we found that one of us saw the "foldaway construction of struts and canvas" as a tent and the other as an early biplane, with potentially significant effects on the type of implications derived.
} 
What is communicated in such cases is sometimes described as a non-propositional effect. Characteristic features of such effects include the fact that

- different audiences paraphrase them in rather different ways;

- no finite paraphrase captures all their nuances;

- they are often described as 'open-ended';

- they typically involve the activation of perceptual, emotional or sensorimotor mechanisms.

Moreover, these effects are not confined to figurative or literary utterances. Suppose that in uttering (1b) above, Sue knows that Jack has put a lot of effort into cooking a special meal to surprise her on her birthday; then her response would communicate a wide array of 'nonpropositional' effects about her attitude not only to the meal but to her relationship with Jack. ${ }^{3}$

'Non-propositional' effects present a challenge to pragmatics. Here we consider how this challenge might be met.

\section{The exclusion of 'non-propositional' effects from pragmatics}

There have been two main responses to the issues raised by interpretive indeterminacy and 'non-propositional' effects. The first is to acknowledge their existence, but to set them aside and focus on determinate propositional components of utterance comprehension, such as generalised conversational implicatures, which are relatively context-independent and more amenable to being formalised and publicly shared. In an often-quoted passage, Grice

\footnotetext{
3 We put 'non-propositional' in scare quotes since we will argue in section 3 that many such effects can be analysed in propositional terms.
} 
(1967/1989: 39-40) acknowledged the indeterminacy of many implicatures, while continuing to render the interpretations of metaphorical and ironical utterances as determinate speaker's meanings. Gerald Gazdar (1979: 40), one of the pioneers of formal pragmatics, followed Grice's lead:

Because indeterminacy is hard to handle formally, I shall mostly ignore it in the discussion that follows. A fuller treatment of implicature would not be guilty of this omission, which is only really defensible on formal grounds.

A similar approach is well-evidenced in the work of Stephen Levinson (2000), which focuses on generalised implicatures and says little about particularised implicatures, metaphor, irony and other figurative uses. In fact, this first response dominates current work in neo-Gricean frameworks, where a concern with generalised scalar implicature has taken a particularly strong hold.

The second response is to treat 'non-propositional' effects as falling entirely outside the scope of a theory of linguistic communication (and hence of pragmatics). Donald Davidson (1978: 46) famously adopted this view in the case of metaphor, arguing that "the thesis that associated with a metaphor is a cognitive content that its author wishes to convey and that the interpreter must grasp if he is to get the message" is simply false. This response is most comprehensively voiced by Lepore and Stone $(2010,2015)$, who maintain that openended interpretive effects must be accounted for by an entirely different kind of theory from the one that explains classic pragmatic phenomena such as indirect speech acts, scalar implicatures and various cases of 'pragmatic enrichment'. In discussing metaphor specifically, they echo Davidson's views: 
The commonplace view about metaphorical interpretation is that it can be characterised in traditional semantic and pragmatic terms, thereby assimilating metaphor to other familiar uses of language. We will reject this view, and propose in its place the view that, though metaphors can issue in distinctive cognitive and discourse effects, they do so without issuing in metaphorical meaning and truth, and so without metaphorical communication. (Lepore and Stone, 2010: 165)

There are some immediate problems for this stance on metaphorical language use. For one thing, it does not explain the fact that metaphorical uses affect truth-conditional content when they occur in embedded positions, as in (6B):

(6) A: Her new boyfriend is a mouse

B: Well, it's better to date a mouse than a rat

Nor does it shed light on the fact that metaphorical meanings can become lexicalised, or that, as cognitive linguists have demonstrated, metaphorical meanings permeate vast swathes of our ordinary vocabulary. More important, it doesn't explain how metaphor interpretation works, apart from saying that it involves a special kind of "perspective taking" (Lepore and Stone: 164-169), nor account for the well-documented commonalities and continuities between metaphorical and other loose uses of language (Wilson and Carston, 2007; Sperber and Wilson, 2008).

In more recent work, Lepore and Stone (2015) extend their arguments from metaphor to a range of other traditional pragmatic phenomena, including all figurative uses of language and much more besides. The claim that grounds this move is that there are two ways in which language productions (spoken or written) can engage our minds. On the one hand, there are linguistic conventions, which are entirely responsible for the public 
propositional content that our utterances convey, which can be entered on the 'conversational register' and contribute to what we take to be our common ground as the exchange proceeds. On the other hand, certain uses of language call for an imaginative engagement with what Lepore and Stone call "the imagery of an utterance" (ibid: 184); these include figurative uses, certain types of evocative literal use, verbal humour and the practice of hinting (which they see as underlying several classic cases of particularised conversational implicature). The kind of imaginative activity at work here has an essentially private significance; although interlocutors may end up sharing insights by such means, these insights are not components of the shared meaning-making endeavour. The cognitive and other kinds of interpretive effects of these more creative language uses cannot be dealt with by any kind of systematic pragmatic theory: "To call these effects pragmatic is to miss both their heterogeneous origins and their non-propositional effects" (ibid: 150). The upshot of Lepore and Stone's account is a strikingly diminished view of pragmatics, on which "Pragmatics merely disambiguates; pragmatic reasoning never contributes content to utterances" (ibid: 83 ). ${ }^{4}$

These responses to the challenge of 'non-propositional' effects raise in acute form the question of where the boundaries of pragmatics should be drawn. If we follow Levinson's suggestion that a theory of communication should target "the full scope of Grice's (1957) non-natural meaning", we already exclude from pragmatics a vast range of overtly intentional non-verbal acts that Grice's definition of speaker's meaning was specifically designed to rule out (see section 1). Grice's proposal led to a long (and often sterile) debate about where the cut-off point between meaning that and showing that should come. This debate, which Grice

\footnotetext{
${ }_{4}^{4}$ For critical reviews of Lepore and Stone (2015), see Bezuidenhout (2016), Carston (2016), Horn (2016), and Preyer (2018).
} 
himself never satisfactorily resolved, ${ }^{5}$ failed to tackle a crucial empirical question: is there a set of pragmatic principles and mechanisms dedicated exclusively to the identification of speaker's meanings, or do the same interpretive principles and mechanisms apply across the full range of overtly intentional communicative acts? Before equating the boundaries of pragmatics with the boundaries of a theory of speaker's meaning, this question needs to be resolved.

The two responses discussed in this section raise comparable questions. For those, like Grice, who see these effects as falling within the scope of pragmatics, the challenge is to show that the pragmatic principles and mechanisms they invoke to deal with determinate speaker's meanings can account for more 'open-ended' interpretive effects such as those illustrated in (2)-(5) above, which are highly context-sensitive and often dependent on contingencies of individual memories and associations. Linguistic pragmaticists have tended to favour amenability to formalisation over coverage of the full range of interpretive effects; cognitive approaches to pragmatics have tended to do the reverse. We believe that the two kinds of enterprise - empirically grounded theory, on the one hand, and formalisation (where possible and insightful), ${ }^{6}$ on the other - can and should proceed together in pragmatics.

For those, like Lepore and Stone, who divide interpretive effects into two totally distinct classes - one a set of usage conventions, the other a heterogeneous class of largely unconstrained associations and inferential leaps - the challenge is to account for the fact that there is no clear cut-off point between speaker's meanings as standardly conceived and more open-ended 'non-propositional' effects, but rather a continuum, with intermediate

\footnotetext{
5 See Grice (1957/1989: chapter 5); Sperber and Wilson (2015).

${ }^{6}$ We are thinking particularly of Bayesian approaches to formalisation; see for instance Franke and Jäger (2016), Goodman and Frank (2016).
} 
cases that exhibit a limited degree of indeterminacy and scope for individual variation. With metaphors, for instance, there is a continuum of degrees of indeterminacy, from heavily conventional uses at one extreme to novel poetic uses at the other (Vega Moreno, 2007). Similar continua exist between speaker's meanings as Grice defined them and the further range of overt intentional communicative acts that Grice's definition was designed to exclude (Sperber and Wilson, 2015).

Relevance theorists set out from the start to look for a set of pragmatic principles and mechanisms that can deal with the full range of overtly intentional communicative acts: verbal and non-verbal, showing and telling, determinate and indeterminate, literal and figurative, propositional and non-propositional (Sperber and Wilson, 1986/1995, 2015; Carston, 2002, 2010; Wilson and Sperber, 2012). In the next section, we turn to recent work on 'non-propositional' effects within this framework.

\section{Beyond speaker's meaning to the inclusion of non-propositional effects}

We want to argue that an inferential theory of communication such as relevance theory can explain the characteristic properties of the full range of interpretive effects, by considering the answers to four questions: (a) what is an ostensive act? (b) what is the intended import of an ostensive act? (c) what is an inference? and (d) what is a proposition (or 'array of propositions')?

\subsection{What is an ostensive act?}

Whether or not they intend to, humans provide perceptual, emotional and sensorimotor information about their mental states all the time, and are constantly engaged in monitoring each other's mental states on the basis of this information. It takes only a slight modification of behaviour for this information to become ostensive: that is, to attract an addressee's 
attention and focus it on the communicator's intentions. Common cues to ostension include catching someone's eye, touching them, pointing, showing them something, speaking and writing. Further possible cues come from the manner in which an action is performed (for instance, the movements of a tennis coach when showing a class how to serve will be slower and more accentuated than when actually serving in a game). In language use, departures from expected syntax, wording or prosody (e.g. the ironical tone of voice in (4) or the exaggerated imitation in (5)) also provide possible cues to ostension, focusing attention on particular aspects of the ostensive act and encouraging a search for additional interpretive effects. Classical rhetoricians were good at listing and classifying such departures, but said little about their interpretive effects, beyond remarking that they add a certain vividness, liveliness or beauty to the text.

\subsection{What is the intended import of an ostensive act?}

Having rejected the notion of a speaker's meaning as too narrow for our purposes, we will describe what is communicated by an ostensive act as its intended import. We see this import as consisting, not necessarily of a single proposition (or small set of propositions), but of an array of propositions which may vary indefinitely in size. At one extreme, this import may consist of a single proposition; at the other, it may consist of a vast array of propositions; and there is a continuum of cases in between.

The intended import of an ostensive act can be conveyed by either showing or telling. By showing you a photograph of the view from my hotel window, I offer you direct perceptual evidence for a vast array of propositions. I might have conveyed some of the same import by telling you about the view: that is, by offering you direct evidence, not of the array of propositions itself, but of my intention to convey it. Showing and telling can combine, as 
when I hand you a photo of the view while describing a particular aspect of it that I want you to focus on, perhaps using a tone of voice or facial expression that reveals something of my emotional attitude. To the extent that the addressee's perceptual, emotional or sensorimotor mechanisms play a role in identifying the intended effects, the array of propositions communicated by an ostensive act may be richer and more fine-grained.

For Grice (1967/1989: 105-112), the communicator's goal in producing a declarative utterance is to make the addressee believe (or believe that she believes) the propositions that make up her meaning $\mathrm{N}_{\mathrm{N}}$. However, the larger the array of propositions, the less plausible it is to think of this array as duplicated in the minds of communicator and addressee; indeed, as noted in section 2, this is one of the main reasons for abstracting away from indeterminacy in pragmatics. We want to argue that the communicator's goal is not necessarily to make the addressee believe a determinate set of propositions which can be individually enumerated in the minds of communicator and addressee, but to alter the addressee's possibilities of thinking: that is, the range of inferences for which he has evidence, and which he is somewhat more disposed to draw as a result of the ostensive act. By producing an ostensive act, the communicator provides a rich variety of information - perceptual, emotional, sensorimotor and (in the case of verbal communication) linguistic and conceptual - about her mental states. By monitoring this information, the addressee is in a position to infera vast array of propositions about the communicator's mental states (and in particular her intentions). Of course, not all the propositions in this array are likely to be equally salient or strongly evidenced; as a result, the effort involved in inferring them will vary and only the most salient and strongly evidenced are likely to end up being mentally represented by the addressee and accepted as true (or probably true). Let us say that a proposition is manifest to an individual to the extent that it is salient and strongly 
evidenced for him - that is, to the extent that he is likely to some positive degree to entertain it and accept it as true (or probably true). We can then claim that the communicator's goal in performing an ostensive act is not necessarily to induce a specific set of beliefs in the addressee, but to make an array of propositions more manifest to him (Sperber and Wilson, 1986/1995: 38-46; 2015).

Ostensive communication can then be defined in terms of two intentions (based on the first two clauses of Grice's definition of speaker's meaning):

\section{Informative intention:}

To make manifest (or more manifest) to the addressee an array of propositions I

\section{Communicative intention:}

To make the informative intention mutually manifest to communicator and addressee $^{7}$

Moreover, communication can be thought of as stronger or weakerdepending on the manifest strength of the speaker's intentions concerning any particular member of the array. In (1b), Sue's intention to inform Jack that she enjoyed some of the meal is strongly manifest, so this proposition would be strongly communicated; the proposition that she didn't enjoy all of the meal would also be strongly communicated - though slightly less so, because of the extra element of inference involved. In (4B) (if uttered today), use of an ironical tone of voice might make fairly strongly manifest B's intention to communicate that she rejects with scorn the idea that Britain rules the seas. She might also weakly communicate an array of implicatures to the effect that she rejects imperialism, disapproves of Britain's foreign policy, may not support Brexit, and so on. The weaker the communication, the less strongly

\footnotetext{
${ }^{7}$ Or, in other words, to add the communicator's informative intention to the common ground.
} 
manifest the speaker's intention, and the more responsibility the addressee has to take for treating a certain proposition as part of the intended import. Eventually, comprehension shades off into a broader process of interpretation where all the responsibility for drawing a certain conclusion falls on the addressee (Wilson, 2018: 187-190).

\subsection{What is inference?}

The function of inferential processes is to yield true, or at least warranted, conclusions. For someone who sees such processes as involving step by step derivation of explicit conceptual conclusions from explicit conceptual premises, the need to appeal to other types of mechanism in order to account for 'non-propositional' effects must seem overwhelming. However, some cognitive scientists have been moving towards broader notions of inference in recent years. As Sperber and Wilson (2015: 137) put it,

Not all inferences involve step by logical step derivations of explicit conclusions from explicit premises. Arguably, the vast majority of inferences made by humans and other animals do not involve such derivations.

An approach along these lines is developed by Mercier and Sperber (2017: 56), who comment:

Cognition involves going well beyond the information available to the senses. All that sensory organs get by the way of information, be it in ants or in humans, are changes of energy at thousands or millions of nerve endings. To integrate this information, to identify the events in the environment that have caused these sensory stimulations, to respond in an appropriate manner to these events, cognition must, to a large extent, 
consist in drawing inferences about the way things are, about what to expect, and about what to do.

On this broader view, inferential processes may take radically different forms from those described in standard logics based on a limited set of deductive rules or axioms. Moreover, perception and memory are both seen as involving a substantial element of inference, and the sensorimotor, emotion- and mind-reading mechanisms are themselves seen as inferential. On this approach, using a relevance-guided comprehension heuristic ${ }^{8}$ to recognise a communicator's intended import on the basis of linguistic, perceptual, emotional and sensorimotor information provided by an ostensive act is an inferential process par excellence (Carston, 2002; Wilson and Sperber, 2012).

\subsection{What is a proposition?}

The notion of a proposition, like the notion of inference, can be more or less narrowly construed. What is essential to a proposition (and hence to a propositional representation as opposed to a sensorimotor representation or emotional state) is that it can be true or false, can be made more or less strongly manifest, and can function as the output of an inference process.

In linguistics and philosophy, propositions are often seen as closely related to the sentences in a public language, and concepts are seen as corresponding roughly one-toone to the words in a language. On this narrow construal, the case for assuming that the output of the comprehension process extends beyond propositions to images, feelings and

\footnotetext{
8 "Follow a path of least effort in deriving cognitive effects. Test interpretive hypotheses in order of salience. Stop when you have enough cognitive effects to satisfy your expectations of relevance" (Sperber and Wilson, 2002: section 5).
} 
states of mind must again seem overwhelming. However, largely as a result of work in pragmatics, there is increasing evidence that the gap between propositions and naturallanguage sentences is much broader than is standardly assumed (Carston, 2002; Recanati, 2010).

Recent work on lexical pragmatics has shown that the gap between language and thought exists not only on the level of whole sentences, but also on the lexical or phrasal level, as speakers may use existing words to convey not their encoded meaning but an 'ad hoc' concept (or occasion-specific sense) which is broader or narrower than the encoded meaning. In (3) above, for instance, kill is hyperbolically used to denote not only acts of killing but also other acts driven by a very strong desire, glass is loosely used to denote containers that may be made of other materials than glass, and water is used to denote, more specifically, water that it is safe to drink. Relevance theorists have argued that humans have many more concepts than words, and indeed, that they can create whole swathes of new concepts for very little effort, using existing concepts as templates, in order to satisfy pragmatic expectations (Sperber and Wilson, 1998; Carston, 2002; Wilson and Carston, 2007). On this broader construal, 'ad hoc' concepts are capable of capturing fine-grained differences in perception, action or emotion in a way that encoded word meanings cannot, and are communicated not by encoding them but by providing evidence of one's intention to convey them.

In this section, we have tried to show how an inferential theory of overt intentional communication can account for the full range of ostensive acts - verbal and non-verbal, literal and figurative, telling and showing, determinate and indeterminate, propositional and 'non-propositional'. In the next section, we return more specifically to the role of mental imagery in comprehension. 


\section{A role for mental imagery?}

The kind of non-propositional effects that many literary theorists and some philosophers allude to are often talked of as mental images. For instance, discussing the now dead metaphor He was burned up, Davidson (1978/84: 38) says, "When the metaphor was active, we would have pictured fire in the eyes or smoke coming out of the ears." Similarly, considering what he calls "image-demanding" metaphors, Green (2017) recalls encountering the metaphor He wiped the floor with me (uttered by Wittgenstein describing his first meeting with Frege) and forming a cartoon-like image of one person literally using another as a means of wiping a floor, before figuring out, from the image together with contextual assumptions, that the speaker was expressing thoughts to do with Frege's intellectual superiority and domination of him. The description of the heron in example (2) above also triggers a visual mental image - of parts of the heron's body (legs, wings, neck and head) moving into position, somewhat awkwardly but purposefully, as it prepares to take flight. For at least some readers, this image, rather than any implications communicated, may be the most pleasing and memorable effect of the description.

The kind of imagery at issue here is consciously experienced (phenomenologically salient). It's not entirely clear what relation it has to the sensorimotor activity ('simulations') that brain imaging studies have shown to be prevalent during conceptual processing, including language processing (Barsalou et al. 2008). However, there is evidence to suggest that the modality-specific simulations automatically triggered by linguistic and pragmatic processes may rise to the level of conscious experience in certain conditions. Focusing again on metaphor, two sets of experimental findings are relevant here: (a) that novel/creative metaphors take longer and are more costly to comprehend than familiar/frozen ones (Giora 2003, Lai et al. 2009); (b) that novel/creative metaphors evoke 
significantly more and longer activation of sensorimotor areas of the brain than familiar/frozen metaphors (Just 2008, Desai et al. 2011). A plausible hypothesis is that the extra time and effort required for understanding a novel/creative metaphor facilitates, and perhaps intrinsically involves, the conscious grasp and manipulation of mental images. The same line of thought applies to non-metaphorical uses of language that induce a hearer/reader to slow down, take more time and expend more effort in reaching an interpretation. For instance, haiku poems typically employ language literally, as in (7) below, but aspects of their form (the three short lines, a specific count and weight of syllables, the use of juxtaposition) encourage the reader to slow down and linger on each line, and each word:

(7) On a leafless bough

A crow is perched -

The autumn dusk.

(Bashō, 1680)

Arguably, as a result of this slower more effortful processing, the sensorimotor simulations triggered by the nominals a leafless bough, a crow, the autumn dusk, and the verb perched are experienced by the reader as visual images, available for mental scrutiny and reflection.

An interesting question here is what relation (if any) there is between this kind of nonpropositional imagistic effect and the array of more or less strongly communicated propositions discussed in section 3. As Sperber and Wilson $(1986 / 1995,2015)$ point out, propositions can be made manifest in many ways, including drawing attention to an object or scene in the world by pointing, using gestures (e.g. an ostensive sigh or sniff), or producing a demonstrative utterance (e.g. Listen to this, Look at that). These are all ways of getting 
addressees to draw on their own perceptual experience in identifying the array of propositions that constitute the intended import of an ostensive act. An idea developed in Carston (2018) is that some metaphors (and other creative uses of language) can achieve something similar by activating mental images and sustaining them above the threshold of consciousness. These images may help to increase the manifestness of an array of propositions which contribute to the relevance of the utterance or text, and which may therefore be accepted as weakly communicated implicatures. In (7), for instance, the visual imagery of the poem (and the feelings it evokes) may make manifest to a reader a vast array of propositions having to do with the landscape, the time of year (impending winter), the end of day (impending darkness), and possibly (through further associations) with aspects of human life such as old age, loneliness and loss, thereby, as Sperber and Wilson (2008: 100) say, "achieving a powerful overall effect which varies to some extent from reader to reader". If this is right, then, in addition to being a source of pleasure in themselves, mental images may play an instrumental role in the interpretation process as a source of relevant implications.

A possible objection to this line of argument might be that mental images are too variable and idiosyncratic to play a reliable role in identifying the intended import of an ostensive act. Another might be that images are informationally dense, so that even if they were stable across individuals, there would be a further issue about how the addressee selects among the indefinite array of propositions made manifest to him. ${ }^{9}$ To respond fully to the first objection, we would need to know much more about the nature of the mental images

\footnotetext{
${ }^{9}$ An anonymous reviewer has suggested that there may be a further type of constraint based on a preference in human visual perception for global rather than local properties of objects, as argued by Reboul (2007).
} 
evoked (including how detailed or schematic they are). However, a strong constraint on the mental images activated is provided by the language itself: this is not unconstrained imaging like daydreaming or fantasizing, but is linguistically guided (in a similar way to the visualizing prompted by the yoga teacher who says, Now, throw away all thoughts about your day, sink down and melt into the floor). Moreover, as discussed above (sections 1, 3), in weaker forms of communication, where the goal is not to achieve exact duplication of thoughts, communicator and addressee(s) may end up entertaining different members of the array of propositions made manifest by an utterance without this constituting a failure of communication. Thus, among the images evoked by the description of a heron as $a$ foldaway construction of struts and canvas, snapping and locking itself into shape just in time to keep airborne (example (2), section 1), some might focus the reader's attention more on the apparently chaotic nature of the takeoff than its successful outcome, while with others, the priorities would be reversed.

As regards the second possible objection, there is an immediate answer that comes directly from the core of the pragmatic theory outlined above: all utterance/text interpretation is strongly constrained by the addressee's expectations of relevance. In identifying the intended import of an ostensive act from among the vast array of propositions made manifest by that act, the addressee is seen as using a relevance-guided comprehension heuristic, a sub-module of a 'mind-reading' module dedicated to attributing mental states to others in order to explain and predict their behaviour (Sperber and Wilson, 2002, 2015).

While the 'non-propositional' effects discussed in section 3 - which we have analysed as arrays of weakly communicated propositions - form part of the intended import of an ostensive act, mental images, which are also often described as "non-propositional effects", do not. Like percepts (and the objects in the world that cause them), mental images are not 
the kind of entity that can be made manifest, and cannot therefore form part of the output of an inferential comprehension process whose goal is to identify the speaker's informative and communicative intentions. However, it doesn't follow that such effects are not foreseen, or even intended, by speakers and writers. Skilled language users are able to exploit the fact that language quite generally and automatically activates sensorimotor simulations by crafting their utterances/texts so as to promote the experience of imagery in their addressees. They may do this by producing novel extended metaphors, or by many other creative uses of language..$^{10}$

\section{Conclusion: the future of pragmatics}

In this short paper, we have tried to show that 'non-propositional' effects, which are a pervasive feature of the type of overt intentional communication that inferential pragmatic theories set out to explain, cannot be adequately dealt with by assuming that Grice's notion of speaker's meaning sets the boundaries on what pragmatic theories should address. As well as accounting for the strongly communicated, highly determinate explicatures and implicatures that constitute prototypical speaker's meanings, pragmatic theories should shed light on those weak propositional effects that form part of the intended import of an utterance or text, and offer some insight into a further range of effects that seem better described in non-propositional terms, as mental imagery and affective states that utterances and texts may activate in a hearer or reader. While weak propositional effects are the outputs of standard inferential comprehension processes, imagery and affective states are

\footnotetext{
10 Some attempts by literary scholars to account for this aspect of the interpretation of literary texts using the framework of relevance theory can be found in Cave and Wilson (2018).
} 
automatically activated by-products of linguistic and pragmatic processes, which may nonetheless be intentionally encouraged by creative uses of language.

In response, then, to the question raised by this special issue, 'Quo vadis, pragmatics?', we think the time has come to address and redress the omission of ‘indeterminacy’ from pragmatics, which, as Gerald Gazdar put it, "is only really defensible on formal grounds", and we suggest that an important direction for future research is to engage in a more thorough investigation of the kind of highly context-dependent 'non-propositional' interpretive effects we have discussed here, while attempting to develop formal tools that can do justice to their richness and variety.

\section{References}

Barsalou, Lawrence, Santos, Ava, Simmons, W. Kyle, Wilson, Christine, 2008. Language and simulation in conceptual processing. In: de Vega, Glenberg, Graesser, (Eds.), pp. $245-84$.

Bezuidenhout, Anne, 2016. What properly belongs to grammar? A response to Lepore and Stone. Inquiry 59 (2), 175-194.

Carston, Robyn, 2002. Thoughts and Utterances: The Pragmatics of Explicit Communication. Blackwell, Oxford.

Carston, Robyn, 2010. Metaphor: ad hoc concepts, literal meaning and mental images. Proceedings of the Aristotelian Society 110, 295-321.

Carston, Robyn, 2016. Linguistic conventions and the role of pragmatics. Review of Lepore and Stone, 2015. Mind and Language 31, 613-25. 
Carston, Robyn, 2018. Figurative language, mental imagery and pragmatics. Metaphor and Symbol 33 (3), 198-217.

Cave, Terence, Wilson Deirdre (Eds.), 2018. Reading Beyond the Code: Literature and Relevance Theory. Oxford University Press, Oxford.

Davidson, Donald, 1978. What metaphors mean. Critical Inquiry 5, 31-47.

Desai, Rutvik, Binder, Jeffrey, Conant, Lisa, Mano, Quintano, Seidenberg, Mark, 2011. The neural career of sensory-motor metaphors. Journal of Cognitive Neuroscience 23 (9), 2376-2386.

de Vega, Manuel, Glenberg, Arthur, Graesser, Arthur, (Eds.), 2008. Symbols and Embodiment. Oxford University Press, Oxford.

Franke, Michael, Jäger, Gerhard, 2016. Probabilistic pragmatics, or why Bayes' rule is probably important for pragmatics. Special Issue: Formal pragmatics. Zeitschrift für Sprachwissenschaft, 35 (1), 3-44.

Gazdar, Gerald, 1979. Pragmatics: Implicature, Presupposition and Logical Form. Academic Press, New York.

Giora, Rachel, 2003. On our mind: Salience, context, and figurative language. New York, NY, Oxford University Press.

Goodman, Noah, Frank, Michael, 2016. Pragmatic interpretation as probabilistic inference. Trends in Cognitive Science 20 (11), 818-829.

Green, Mitchell, 2017. Imagery, expression, and metaphor. Philosophical Studies 174, 3346.

Grice, H. Paul, 1957. Meaning. Philosophical Review 66, 377-388. Reprinted in Grice, 1989, pp. 213-223. 
Grice, H. Paul, 1967. Logic and conversation. William James Lectures. Reprinted in Grice, 1989, pp. 1-143.

Grice, H. Paul, 1989. Studies in the Way of Words. Harvard University Press, Cambridge, MA.

Horn, Laurence, 2016. Conventional wisdom reconsidered. Inquiry 59 (2), 145-162.

Just, Marcel. 2008. What brain imaging can tell us about embodied meaning. In: de Vega, Glenberg, Graesser (Eds.), pp. 75-84.

Lai, Vicky, Curran, Tim, Menn, Lisa, 2009. Comprehending conventional and novel metaphors: An ERP study. Brain Research 1284, 145-155.

Lepore, Ernie, Stone, Matthew, 2010. Against metaphorical meaning. Topoi 29 (2), 165-180.

Lepore, Ernie, Stone, Matthew, 2015. Imagination and Convention: Distinguishing Grammar and Inference in Language. Oxford University Press, Oxford.

Levinson, Stephen, 1983. Pragmatics. Cambridge University Press, Cambridge.

Levinson, Stephen, 2000. Presumptive Meanings: The Theory of Generalized Conversational Implicature. MIT Press, Cambridge, MA.

Macfarlane, Robert, 2013. The Old Ways: A Journey on Foot. Penguin, London.

Mercier, Hugo, Sperber, Dan, 2017. The Enigma of Reason: A New Theory of Human Understanding. Allen Lane, London.

Preyer, Gerhard (Ed.), 2018. Beyond Semantics and Pragmatics. Oxford University Press, Oxford.

Reboul. Anne, 2007. Langage et Cognition Humaine. Presses Universitaires de Grenoble, Grenoble.

Recanati, François, 2010. Truth-Conditional Pragmatics. Oxford University Press, Oxford. 
Sperber, Dan, Wilson, Deirdre, 1986. Relevance: Communication and Cognition. Blackwell: Oxford. $2^{\text {nd }}$ edition, 1995.

Sperber, Dan, Wilson, Deirdre, 1998. The mapping between the mental and the public lexicon. In: Carruthers, P., Boucher, J. (Eds.), Language and Thought: Interdisciplinary themes. Cambridge University Press, Cambridge, pp. 184-200. Sperber, Dan, Wilson, Deirdre, 2002. Pragmatics, modularity and mindreading. Mind and Language 17, 3-23.

Sperber, Dan, Wilson, Deirdre, 2008. A deflationary account of metaphors. In: Gibbs R. (Ed.), The Cambridge Handbook of Metaphor and Thought. Cambridge University Press, Cambridge, pp. 84-105.

Sperber, Dan, Wilson, Deirdre, 2015. Beyond speaker's meaning. Croatian Journal of Philosophy, 15 (2), 117-149.

Vega Moreno, Rosa, 2007. Creativity and Convention: The Pragmatics of Everyday Figurative Speech. John Benjamins, Amsterdam.

Wilson, Deirdre, 2018. Relevance theory and literary interpretation. In: Cave and Wilson (Eds.), pp. 185-204.

Wilson, Deirdre, Carston, Robyn, 2007. A unitary approach to lexical pragmatics: Relevance, inference and ad hoc concepts. In Burton-Roberts, N. (Ed.), Pragmatics. Palgrave, Basingstoke, pp. 230-59.

Wilson, Deirdre, Sperber, Dan, 2012. Meaning and Relevance. Cambridge University Press, Cambridge. 